\title{
Improving Storability of "Nanfeng" Mandarins by Treating with Postharvest Hot Water Dipping
}

\author{
İbrahim Kahramanoğlu $\mathbb{D},{ }^{1}$ Chuying Chen, ${ }^{2}$ Yao Chen, ${ }^{2}$ Jinyin Chen $\mathbb{D}^{2,3}{ }^{2,3 e n g y u ~ G a n,}$ \\ and Chunpeng Wan ${ }^{2}{ }^{2}$ \\ ${ }^{1}$ European University of Lefke, Northern Cyprus, via Mersin 10, Gemikonagi, Turkey \\ ${ }^{2}$ Jiangxi Key Laboratory for Postharvest Technology and Nondestructive Testing of Fruits \& Vegetables, \\ Collaborative Innovation Center of Postharvest Key Technology and Quality Safety of Fruits \& Vegetables in Jiangxi Province, \\ College of Agronomy, Jiangxi Agricultural University, Nanchang 330045, China \\ ${ }^{3}$ Pingxiang University, Pingxiang 337055, China
}

Correspondence should be addressed to Jinyin Chen; jinyinchen@126.com and Chunpeng Wan; chunpengwan@jxau.edu.cn

Received 13 November 2019; Revised 31 December 2019; Accepted 23 January 2020; Published 27 February 2020

Academic Editor: Maria Rosaria Corbo

Copyright $\odot 2020$ İbrahim Kahramanoğlu et al. This is an open access article distributed under the Creative Commons Attribution License, which permits unrestricted use, distribution, and reproduction in any medium, provided the original work is properly cited.

\begin{abstract}
The current research aimed at studying the possibility of improving the postharvest storability of "Nanfeng" mandarins by hot water dipping (HWD) treatment. The research was conducted in two phases. Firstly, two different temperatures $\left(50\right.$ and $\left.55^{\circ} \mathrm{C}\right)$ were tested for three different dipping durations $(2,3$, and $4 \mathrm{~min}$ ) on the mandarin fruits, and the best combination was defined for the prevention of weight loss and fruit decay. Next, the optimal treatment (HWD at $50^{\circ} \mathrm{C}$ for $3 \mathrm{~min}$ ) was used in further studies to test the effects on the postharvest fruit quality attributes. Regular measurements were performed to determine total soluble solid (TSS) content, titratable acid (TA) content, vitamin C (VC) content, total sugar content, respiration rate, malondialdehyde (MDA) content, and activities of superoxide dismutase (SOD) enzyme, polyphenoloxidase (PPO) enzyme, and peroxidase (POD) enzyme. According to the results obtained, HWD treatment was found to prevent the loss of TSS, TA, and VC contents during the storage period. The HWD-treated fruits were also found to have a lower respiration rate and MDA content as compared with control treatment. Furthermore, HWD treatment significantly enhanced the activities of SOD, POD, and PPO which are known to enhance tolerance to lipid peroxidation and are associated with the fruit protection from injuries and pathogens. Present results also suggest that the activation of the SOD and POD enzymes is highly related to the respiratory activities of the fresh produce. This suggests that the HWD can be used to improve the storability of "Nanfeng" mandarins by maintaining the postharvest physical and biochemical quality.
\end{abstract}

\section{Introduction}

Mandarin fruits are grouped into nonclimacteric fruits which do not ripen after harvest, but are responsive to the postharvest applied ethylene. Mandarins are rich in nutrients, antioxidants, vitamin $\mathrm{C}$, and phenolic and other bioactive compounds and are traditionally and scientifically known to be very beneficial for human health [1]. Cultivation of this highly valuable crop was reported to originate from China and ancient Egypt and is suitable to be grown anywhere with Mediterranean climates [2]. Total world production was about 51.6 million tonnes in 2017, where about $35.2 \%$ is produced only in China [3]. Mandarins are among the important fruits in world trade, where the consumers' demand on mandarin fruits has been increasing throughout the world [4]. Mandarin fruits are sensitive to postharvest storage conditions, mainly to weight loss, chilling injury, and decay, and correct handling practices are important to reduce postharvest losses [5, 6]. Moreover, VC content, antioxidants, soluble sugar, titratable acidity, and phenolic compounds are also greatly affected by postharvest storage conditions [7]. It was reported for the developing 
countries that the postharvest losses due to fungal spoilage exceed $50 \%$ of stored products in a year [8]. Numerous agrochemicals, i.e., imazalil, propiconazole, and thiabendazole, have been utilised for many years to manage postharvest fungal diseases [9], but global attention of the consumers is moving towards the alternative physical and/or biological methods and is not preferring the produce with the use of agrochemicals $[8,10]$.

High storage temperatures increase respiration and transpiration, which enhance fruit senescence, and low temperatures cause chilling injury and are reported to increase the accumulation of volatile compounds, which cause off-flavour at mandarins [11]. The recommended optimum temperature for postharvest storage of mandarins is $5-8^{\circ} \mathrm{C}$, which is above the chilling temperature zone and below the maximum limit for optimum respiration rate $[11,12]$. Previous research studies reported that the utilisation of some handling practices, i.e., edible coatings $[13,14]$, wrapping [15], pectin [16], salicylic acid [17], and plant extracts or its main constituents $[18,19]$, helps to preserve the postharvest quality of citrus fruits. Numerous previous studies also reported that high temperature preconditioning ( 37 to $55^{\circ} \mathrm{C}$ for 3 days to $3 \mathrm{~min}$ ) helps to alleviate chilling injury at different fresh products. Numerous studies reported high success for the hot water dipping (HWD) treatment on different products in terms of the prevention of postharvest losses and quality retention $[20,21]$. The use of heat treatment against chilling injury has been studied extensively, but very few studies have been carried out on the influences of heat treatment on fruits' biochemical changes and its antifungal activity. The potential effects of HWD on the biochemical changes need further studies for a clear understanding of the mechanism. Superoxide dismutase (SOD) and peroxidase (POD) enzymes are reported to alleviate lipid peroxidation $[22,23]$, while polyphenoloxidase (PPO) enzymes are known to enhance disease resistance in plant tissues [24]. Therefore, enhancing the activity of these enzymes would delay fruit senescence and improve the storability of fresh produce. In line with this information, the present study aimed at improving the storability of "Nanfeng" mandarins by treating with postharvest hot water dipping (HWD) and at studying some of the biochemical changes during cold storage. Impacts of HDW on the weight loss and fruit decay, as well as on the total soluble solid (TSS) content, titratable acidity (TA) content, vitamin $\mathrm{C}$ (VC: ascorbic acid) content, total sugar content, respiration rate, malondialdehyde (MDA) content, SOD activity, POD activity, and PPO activity, were studied in the present research.

\section{Materials and Methods}

2.1. Materials. Current studies are conducted with "Nanfeng" mandarins (Citrus reticulata Blanco cv. 97-2) which are collected from an orchard established in Nanfeng (Jiangxi, China) in November 2012 (preliminary experiments for screening the suitable HWD condition) and in November 2013 (further studies to investigate the preservation effects). The fruits were harvested based on fruit size (40-50 g) and color (citrus color index, 2.5-3.2). Fruits were then selected to eliminate any fruits with mechanical injury, blemish, or diseases.

2.2. Preliminary Experiments. Before conducting further studies with chemical analysis, a preliminary experiment was conducted to evaluate the preservation effects of hot water dipping (HWD) on the decay rate and weight loss. Preliminary experiments were conducted in 2012 with the fruits which were harvested in November. Two different water temperatures $\left(50\right.$ and $\left.55^{\circ} \mathrm{C}\right)$ with three different dipping durations (2, 3, and $4 \mathrm{~min}$ ), together with one control (no treatment), were tested in the preliminary experiments. Preliminary experiments were carried out with a total of 2100 fruits. Each experiment (\#7) consists of 300 fruits $(100 * 3$ replications). After treating the fruits with the mentioned applications, the fruits from the control group and the six HWD treatments were individually film-packaged and stored at $6 \pm 0.5^{\circ} \mathrm{C}$. The relative humidity $(\mathrm{RH})$ of the inner atmosphere was also adjusted to $85-90 \%$ and regulated continuously during the storage. Weight loss and decay rate for each group were recorded at $90 \mathrm{~d}$ after storage.

2.3. Evaluation of Decay Rate and Weight Loss. Fruit decay rate of the "Nanfeng" mandarins was determined at the end of the storage period (90 days) of preliminary studies visually by assessing each fruit. The number of rotted fruits was counted and noted to calculate the percentage of rotted fruits. All fruits (\#100) of the 3 replications of each treatment (totally 300 fruits for each treatment) were used for the determination of the decay rate. Weight loss determination was then conducted with 20 fruits (randomly selected) from each replication of each treatment (totally 60 fruits for each treatment). The initial weights of each fruit were measured and noted at the beginning of the experiments. Thus, at the end of the storage period, final weights were then measured and noted. The weight of each fruit was measured with a digital scale $( \pm 0.01 \mathrm{~g})$. Weight loss (\%) was calculated by dividing the weight loss (final weight - initial weight) to the initial weight and multiplying with 100 . Next, the average weight loss was calculated for each treatment.

2.4. Further Experiments. Results of preliminary studies showed that the $\mathrm{HWD}$ at $50^{\circ} \mathrm{C}$ for $3 \mathrm{~min}$ has the highest impact on the prevention of weight loss and reducing the decay rate. Thus, further studies were carried out with this treatment. These studies were conducted in 2013 with the fruits which were harvested in November 2013. This experiment consists of 570 fruits in total. 30 fruits $(10 * 3$ replications) out of 570 were used to measure the initial quality characteristics of the fruits to enable further comparison. The other 540 fruits were randomly divided into two groups (HWD-treated and nontreated control) each containing 270 fruits. The HWD-treated fruits were dipped in hot water at $50^{\circ} \mathrm{C}$ for $3 \mathrm{~min}$. Then, both HWD-treated and control fruits were individually film-packed $(18 \mathrm{~cm} \times 15 \mathrm{~cm}$, Lingqu Fresh Packaging Products Co. Ltd., Guilin, China) and precooled $\left(10-12^{\circ} \mathrm{C}, 12 \mathrm{~h}\right)$. Finally, all fruits were stored 
at the same conditions with preliminary experiments $\left(6 \pm 0.5^{\circ} \mathrm{C}\right.$ and $\left.85-90 \% \mathrm{RH}\right)$. Studies were continued for 90 days, and biochemical parameters were analyzed with 10 day intervals for both treated and untreated fruits. At each of these measurement points $(10,20,30,40,50,60,70,80$, and 90 days), 30 fruits ( $10 * 3$ replications) from each treatment (HWD-treated and control groups) were randomly taken out for analyzing TSS content, TA content, VC content, total sugar content, respiration rate, MDA content, SOD activity, POD activity, and PPO activity.

\subsection{Biochemical Quality Analysis}

2.5.1. TSS and Total Sugar. At each sampling point $(10,20$, $30,40,50,60,70,80$, and 90 days), 30 fruits (10*3 replications) from each treatment (HWD-treated and control groups) were randomly taken out from the storage conditions and the total soluble solid (TSS) and total sugar of the juice samples were determined. The TSS content (\%) was measured by using a RA-250WE Brix-meter (Atago, Tokyo, Japan), while the anthrone colorimetric method was used to assess the total sugar content (\%) of the samples.

2.5.2. TA and VC. The juice extracts of the same fruits (used for analyzing the TSS and total sugar) were used to determine TA and VC contents. The standard method described by AOAC [25] was used to assess TA by titrating the samples with $0.1 \mathrm{M} \mathrm{NaOH}$ to an endpoint of $\mathrm{pH}$ 8.1. The assessment of VC content was then carried out by titration with 2,6dichlorophenol indophenol.

2.5.3. Respiration Rate. The respiration rates of the fruits treated with HWD and control groups were determined according to the method of Chen et al. [18]. At each sampling point $(10,20,30,40,50,60,70,80$, and 90 days), the respiration rate was measured by the $\mathrm{CO}_{2}$ production of 30 fruits (for each treatment) by using a GHX-3051H infrared $\mathrm{CO}_{2}$ fruit and vegetable breathing apparatus (Jingmi Scientific LLC., Shanghai, China), and the results were expressed as $\mathrm{mg} \mathrm{kg}^{-1} \mathrm{~h}^{-1}$.

2.5.4. MDA Content. The malondialdehyde (MDA) content of the HWD-treated and untreated control groups was assessed according to the method described by Hodges et al. [26]. MDA content determination was performed at each sampling point for each of the fruits (30 fruits for each treatment). Peel tissues of fruits were ground and used for the analysis. The MDA content of the samples was expressed as $\mathrm{mmolg}^{-1}$ fresh weight (FW).

2.5.5. Protective Enzyme Activities. Similar to the other biochemical analyses, 30 fruits from each treatment were taken out from the storage rooms at each sampling point and the SOD, POD, and PPO activities were assessed. The modified method of Ballester et al. [22] by Chen et al. [14] was used to determine the SOD, POD, and PPO activities of the HWD-treated and control fruits. SOD, POD, and PPO activities were measured and expressed as $\mathrm{U} \min ^{-1} \mathrm{~g}^{-1}$.

2.6. Statistical Analysis. Raw data of the preliminary experiments with 7 different treatments were subjected to the analysis of variance to determine if there is significant difference among the treatments, and the mean separations were assessed according to Duncan's multiple range test $(P<0.05)$. The comparison of further data about the biochemical parameters from two treatments (HWD-treated and control groups) was then assessed with the independentsamples $t$-test at $P<0.05$. SPSS software (version 17.0, SPSS Inc., Chicago, IL) was used for the statistical analysis, and the results are expressed as the mean with standard error (SE) for different treatments. R 3.6.2 statistical program was used to perform principal component analysis (PCA) and Pearson correlation analysis.

\section{Results}

3.1. Hot Water Dipping (HWD) Treatments on Decay Rate and Weight Loss of Nanfeng Mandarin. Weight loss and decay rate are the two most important indicators of the postharvest quality of fresh horticultural products. Results of the present study suggested that all treatments (except HWD at $55^{\circ} \mathrm{C}$ for $4 \mathrm{~min}$ ) were effective in prevention of the fruit decay and in protection of the fruit weight (Figure 1).

Among the tested treatments, $\mathrm{HWD}$ at $50^{\circ} \mathrm{C}$ for $3 \mathrm{~min}$ was more effective than the others. The decay rate at the fruits treated with $\mathrm{HWD}$ at $50^{\circ} \mathrm{C}$ for 3 min was only $4.33 \%$ at the $90^{\text {th }}$ day of storage, while it was counted as $26.67 \%$ at the control treatment. The efficacy of the treatments was found to be lower at higher temperatures. Similar results were found for the weight loss. At the end of the storage period, weight loss was $5.25 \%$ at the control treatment and was $4.42 \%$ at the fruits treated with $\mathrm{HWD}$ at $50^{\circ} \mathrm{C}$ for $3 \mathrm{~min}$. According to these results, $\mathrm{HWD}$ at $50^{\circ} \mathrm{C}$ for $3 \mathrm{~min}$ was found to be the most effective temperature and duration combination, and it was decided to be compared with the control treatment in the further studies.

\subsection{Effects of HWD on Postharvest Fruit Quality of Nanfeng} Mandarin. TSS, TA, and VC contents of fruits are among the most important postharvest quality parameters of mandarin fruits. Further studies showed that the HWD treatment has a significant influence on the total soluble solid (TSS) content of the fruits; however, this impact began to appear 30 days after storage (Figure 2).

The TSS content of the HWD-treated fruits was found to be higher than that of the control fruits from the $30^{\text {th }}$ day of storage until the end of the experiments (90 days of storage). The fruit TSS was found to increase during the initial periods of storage and then to decrease after 30 days of storage. At the beginning of the experiments, the TSS of the HWDtreated and control fruits was $14.80 \%$ for both, and it decreased to $14.56 \%$ and $14.33 \%$, respectively. Results showed that the HWD treatment is effective in maintaining fruit TSS. Similar results were found for TA, VC, and total sugar 


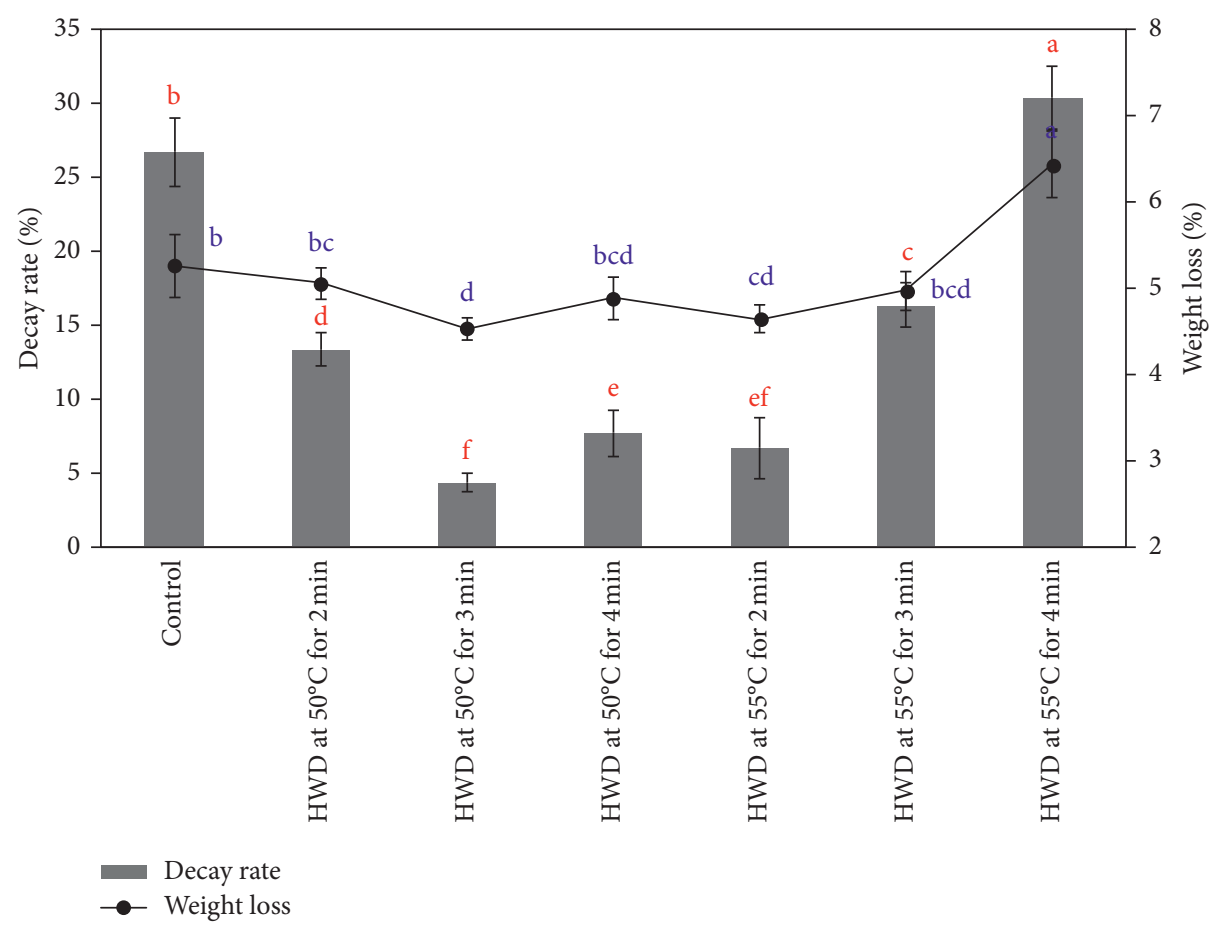

FIGURE 1: Effect of different HWD treatments on decay rate and weight loss of "Nanfeng" mandarin stored at $6 \pm 0.5^{\circ} \mathrm{C}$ for 90 days. Values are the mean $\pm S E$.

contents of the fruits. According to the results, 30 days of storage is a critical period for the occurrence of chilling injury and the physiological changes began. Similar trend was found for the total sugar content during the storage and at the end of the storage period, and HWD-treated fruits were found to have higher total sugar content. The TA content of the fruits showed a decreasing trend during the storage period, and the control fruits showed a higher trend than the HWD-treated fruits. At the end of the storage period, the TA of the HWD-treated fruits decreased from $0.85 \%$ to $0.45 \%$, while that of the untreated control fruits decreased to $0.38 \%$. The trend of the VC content was similar to the TSS and total sugar contents; however, the effectiveness of the HWD-treated fruits was observed since the first measurement (10 days of storage). At the end of the storage period, the HWD-treated fruits were found to have

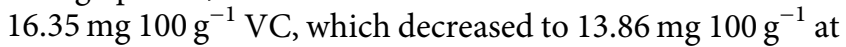
the untreated control fruits.

3.3. Effect of HWD on Respiration Rate and MDA Content of Nanfeng Mandarin. Respiration is among the most important factors determining the postharvest quality and storability of fresh products. It converts stored sugars into energy and increases weight loss [27]. Storing fruits at low temperatures is the most effective way for decreasing the respiration rate. Results of the present study showed that the respiration rate of the mandarins decreased gradually during the first phases of the cold storage (until 60 days of storage) and reached its valley values and then it showed an increase (Figure 3). Results also showed that the HWD-treated fruits have a lower respiration rate than the untreated control fruits. Malondialdehyde (MDA) is the end product of lipid peroxidation which is known to increase while chilling injury increases [16]. Thus, determination of the MDA content is an important measure for the determination of the chilling injury and oxidative damage on the cells. According to the results obtained, the MDA content of the fruits increased considerably during the cold storage; however, the fruits treated with HWD were found to have lower values than control. Current results suggested that the HWD treatment is highly active in reducing the MDA content of the fruits, which is a sign of the improvement of the fruits postharvest quality.

3.4. Effects of HWD on SOD, POD, and PPO Activities of Nanfeng Mandarin. Superoxide dismutase (SOD) and peroxidase (POD) enzymes are reported to alleviate lipid peroxidation $[22,23]$, while polyphenoloxidase (PPO) enzymes are known to enhance disease resistance in plant tissues [24]. For this reason, further studies were also aimed at measuring the change in SOD, POD, and PPO activities during the cold storage. As shown in Figures 4(a) and 4(b), the SOD and POD activities of the mandarins increase during the initial periods of the cold storage and then, after reaching a peak, they began to decrease. The SOD activity of the untreated control fruits reached the peak in 40 days, while the HWD-treated fruits required 60 days to reach the peak. Similar results were observed for POD, while the control fruits reached peak in 30 days and the HWD-treated fruits reached in 50 days. Here, the HWD-treated fruits were found to have higher SOD and POD activities than the untreated control fruits. The PPO activity of the "Nanfeng" 


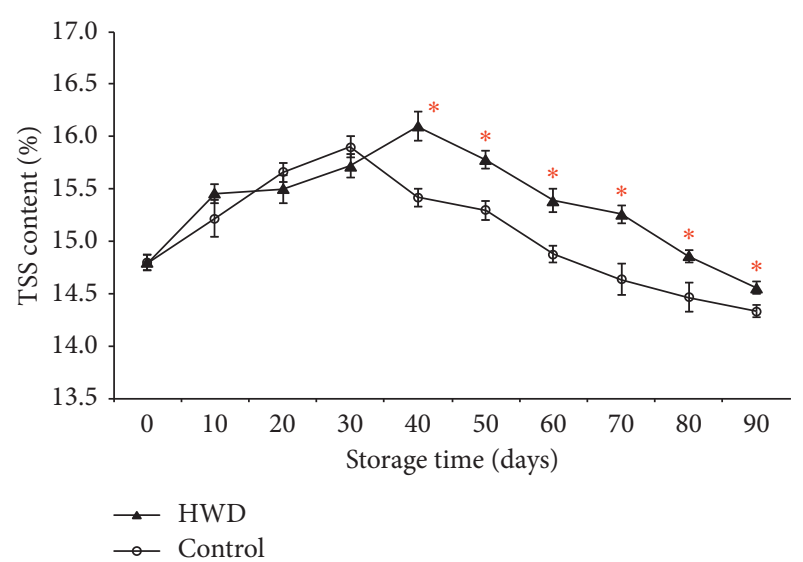

(a)

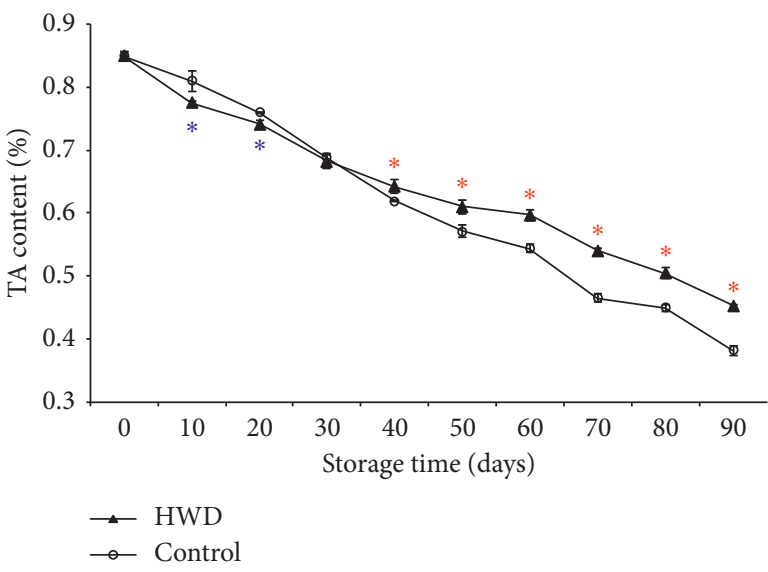

(c)

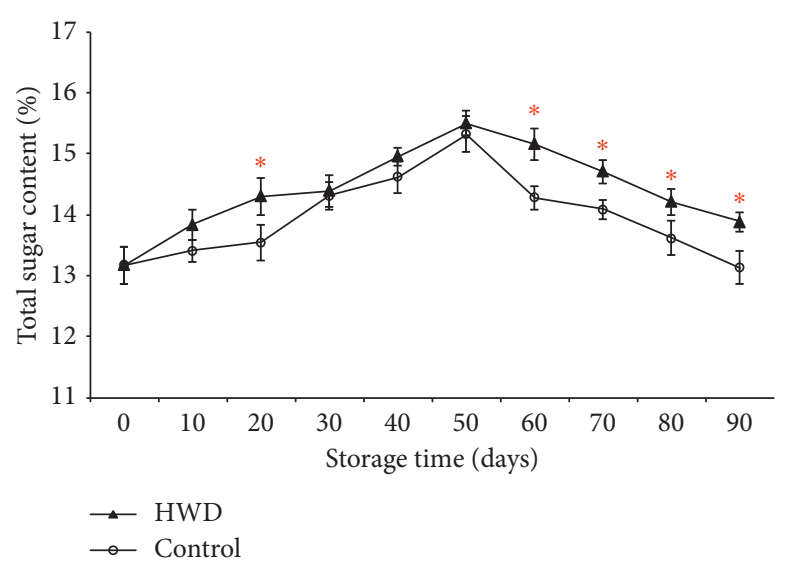

(b)

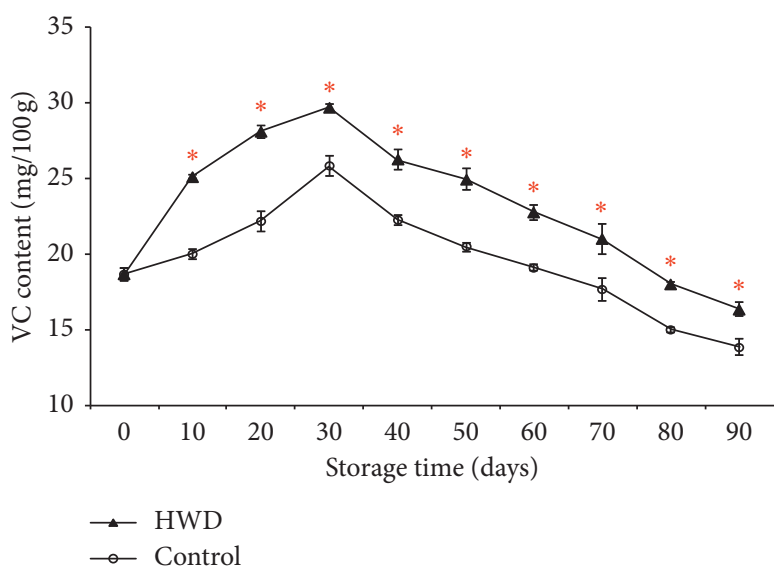

(d)

FIGURE 2: Effects of HWD on the contents of TSS (a), total sugar (b), TA (c), and VC (d) of "Nanfeng" mandarin during 90 days of cold storage at $6 \pm 0.5^{\circ} \mathrm{C}$. The symbols " *" and " $* *$ " represent significantly higher and lower values for the HWD-treated fruits than the control fruits, respectively. The significant difference was determined according to the independent-samples $t$-test $(P<0.05)$ on each storage day.

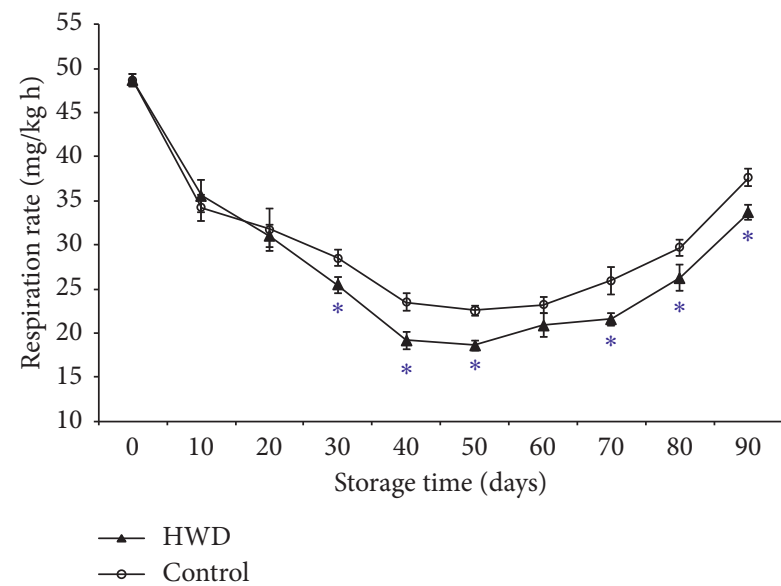

(a)

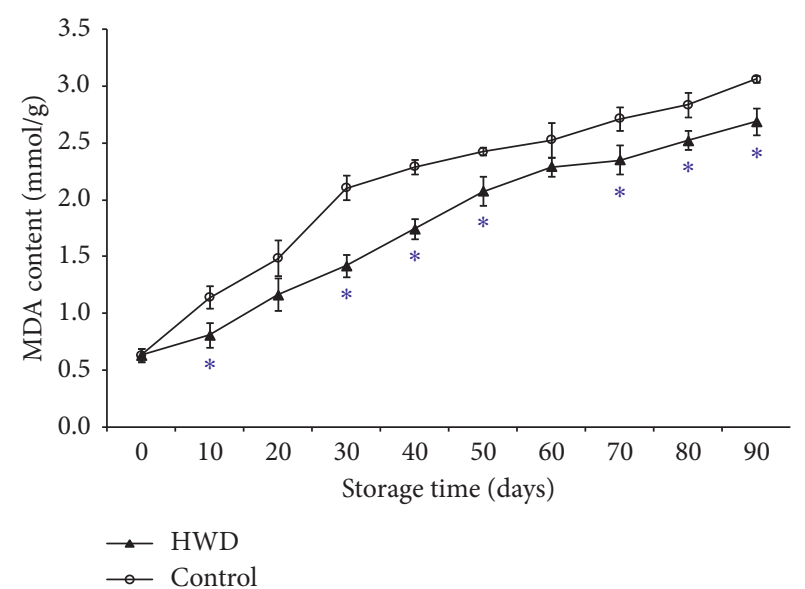

(b)

FiguRE 3: Effect of HWD on respiration rate (a) and MDA content (b) of "Nanfeng" mandarin during 90 days of cold storage at $6^{\circ} \mathrm{C}$. The symbol * represents significantly lower values for the HWD-treated fruits than the control fruits. The significant difference was determined according to the independent-samples $t$-test $(P<0.05)$ on each storage day. 


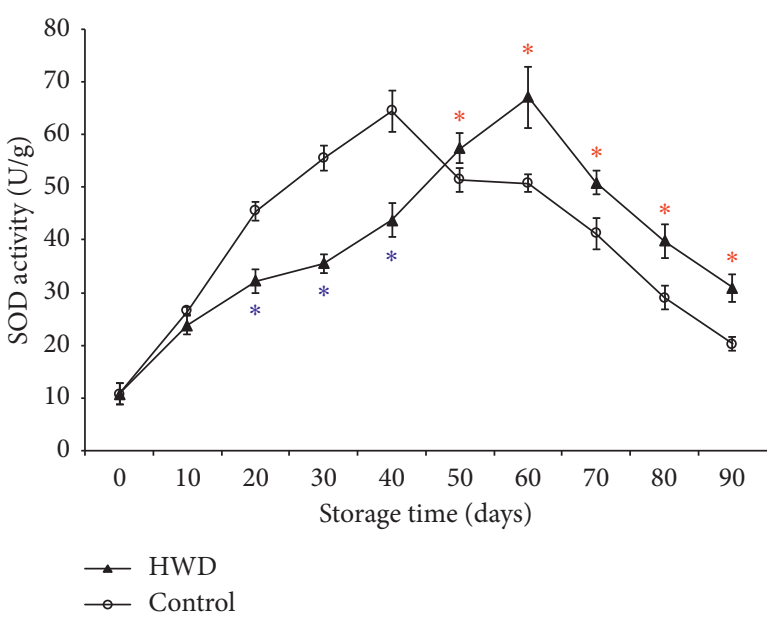

(a)

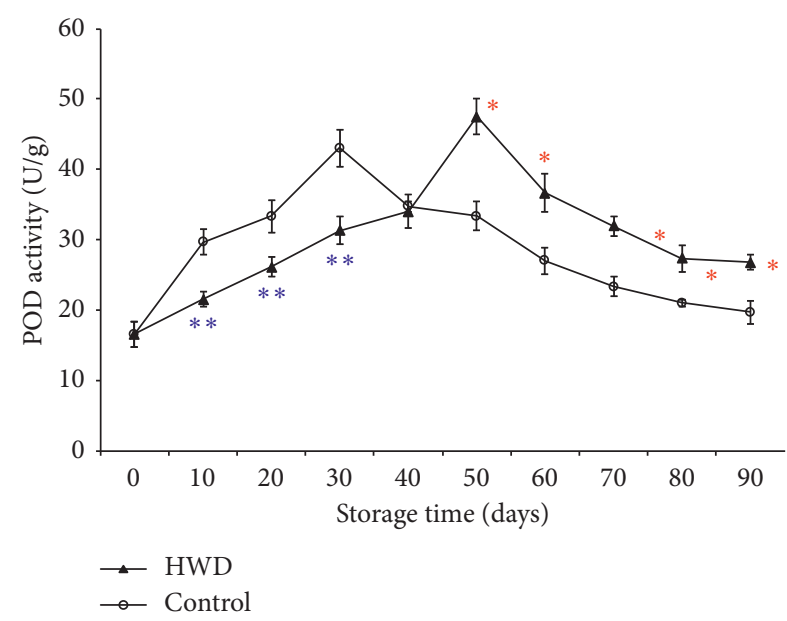

(b)

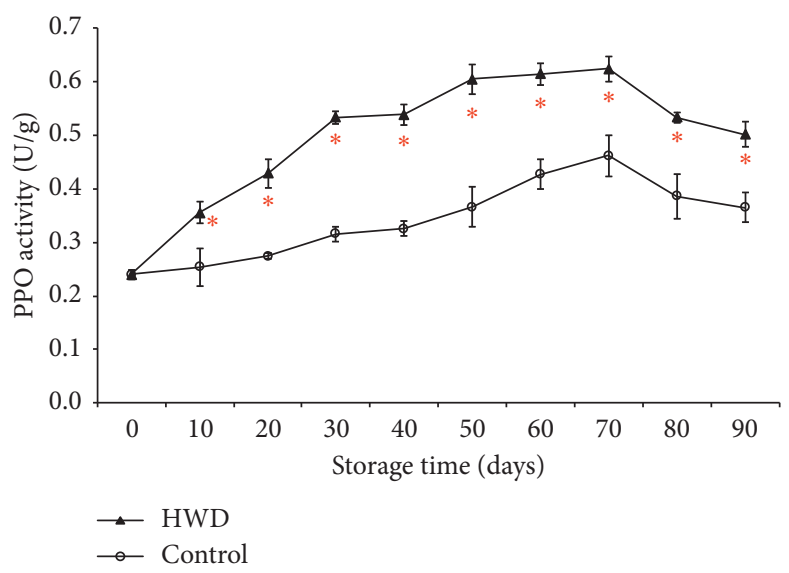

(c)

Figure 4: Effects of HWD on enzyme activities of SOD (a), POD (b), and PPO (c) of "Nanfeng" mandarin during 90 days of cold storage at $6^{\circ} \mathrm{C}$. The symbols “*” and “**” represent significantly higher and lower values for the HWD-treated fruits than the control fruits, respectively. The significant difference was determined according to the independent-samples $t$-test $(P<0.05)$ on each storage day.

mandarins was found to be different than the SOD and POD activities. The peak time of the PPO activity was on the $70^{\text {th }}$ day of cold storage (Figure 4(c)). On the other hand, during the whole storage period, the fruits treated with HWD were found to have higher PPO activities than the untreated control fruits.

3.5. PCA and Pearson Correlation Analysis. A PCA was performed to assess the effectiveness of HWD treatment on the biochemical changes. Eigenvalues of the covariance matrix suggested that the two principal components (PCs) are able to account for $79.47 \%$ of the total variance in the dataset. PC1 was found to explain $49.07 \%$ and the PC2 explained an additional $30.40 \%$ of the variance. PC1 was found to have high positive loadings for the POD, SOD, RR, and TS while high positive loading was observed on PC2 by TA and MDA. PCs made it possible to have a clear separation among the variables and help to identify their relationships (Figure 5(a)). The results also showed that the enzymatic activities were differently impacted by hot water dipping treatment (Figure 5(b)). Shifts in the average PC scores from positive to negative were observed for the HWD-treated fruits. This means that the HWD-treated fruits exhibited less oxidative stress as compared with the control group.

Pearson correlation was used to evaluate the positive and negative relationships among the study parameters (Figures 6(a)-6(c)). The TSS was found to be positively correlated with VC in both HWD-treated and control groups. On the contrary, it was found to have a moderate negative correlation with the respiration rate at the HWDtreated fruits, while the correlation was negligible at the control group. Furthermore, the TSS was positively correlated with PPO at the control group of fruits. Moreover, the TA was significantly correlated with MDA and PPO at all fruits. A weak negative correlation was also observed between the VC and MDA contents. One of the most important correlations was found between the TS and RR, which was negative showing that the increase in respiration rate causes a decrease in the total sugar content. At the same time, the TS content of the HWD-treated fruits was found to 


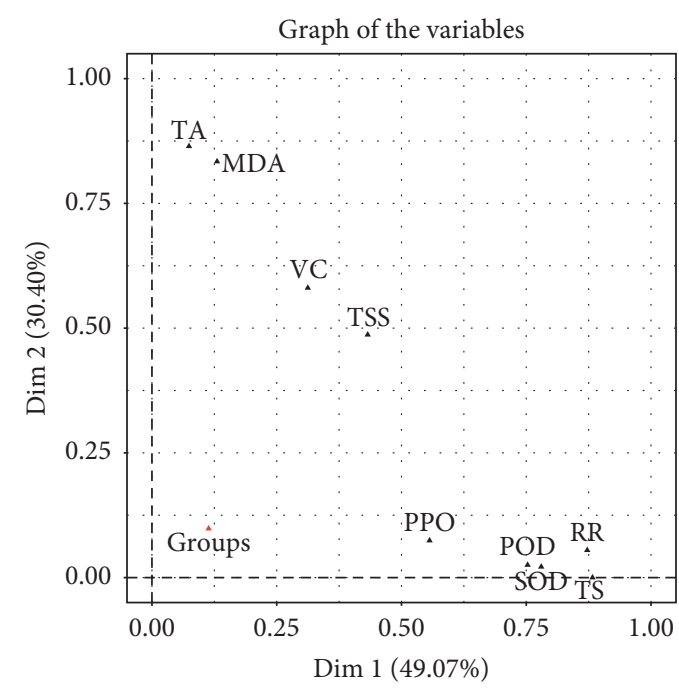

(a)

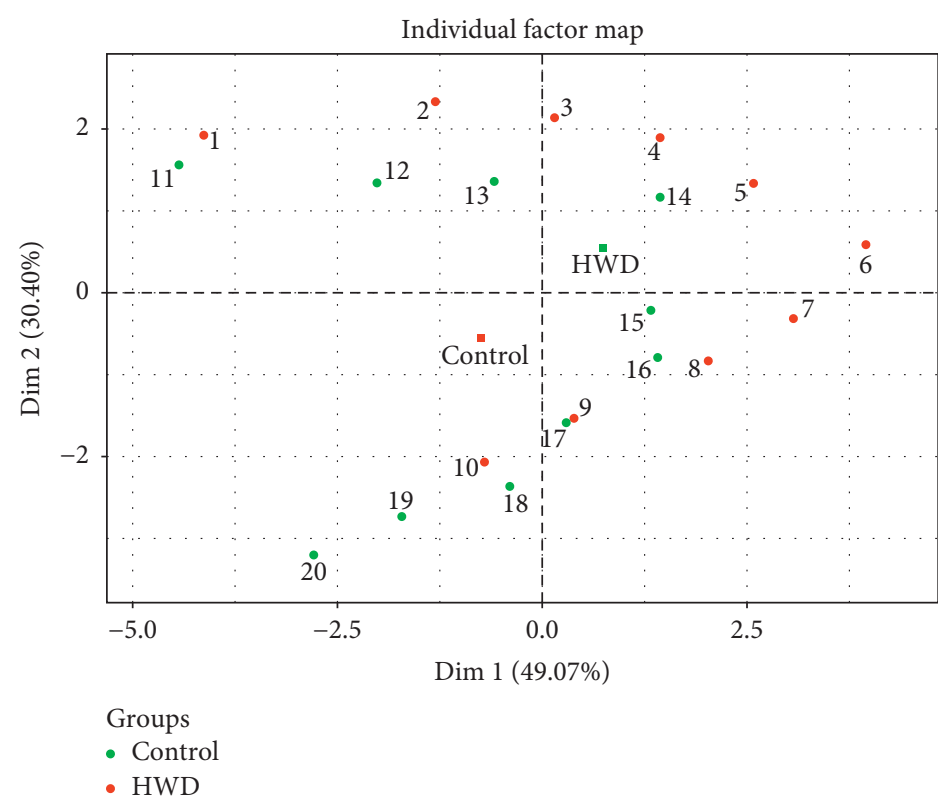

(b)

Figure 5: Two-dimensional principal component analysis (PC1: 49.07\% and PC2: 30.40\%) of the biochemical quality parameters during storage. (a) Graph of the variables and (b) individual factor map (TA: titratable acidity; MDA: malondialdehyde content; VC: vitamin C; TSS: total soluble solids; PPO: polyphenoloxidase; POD: peroxidase; SOD: superoxide dismutase; RR: respiration rate; TS: total sugar).

be positively correlated with the SOD, POD, and PPO enzymatic activities. This correlation was low at the control group while the enzymatic activities of the control fruits were low. The other important correlation was recorded between the MDA and PPO. Similarly, a high positive correlation was found among the SOD, POD, and PPO enzymes at the HWD-treated fruits. However, this correlation was negligible at the control group of fruits, except between SOD and POD.

\section{Discussion}

Heat treatment is a well-known and widely used method for the prevention of chilling injury and fungal decay [28]. Current study supported this background information and made it possible to optimize temperature and duration combination for the "Nanfeng" mandarins for postharvest quality preservation. Present results are novel for "Nanfeng" mandarins and reveal that the optimum conditions significantly vary among different crops. Results of the present study showed that the HWD treatment increases SOD, POD, and PPO activities and reduces the respiration rate and MDA content. These results are associated with a lower weight loss and prevention of fruit decay. Similarly, Wang et al. [29] reported that hot water treatment increases SOD activities which in turn results with a decrease in Rhizopus rot in peach. HWD was also reported to reduce decay incidence and maintain the firmness of muskmelon fruit [30]. Erkan et al. [31] noted that the heat treatments, either hot water dipping or curing with hot air, were effective for reducing decay and chilling injury in "Clementine" mandarins. In a different study with cv. "Wuzishatangju" mandarins, it was reported that the hot water treatment $\left(45^{\circ} \mathrm{C}\right.$ for $\left.2 \mathrm{~min}\right)$ provides higher efficacy on the control of Penicillium digitatum and $P$. italicum without damaging fruit quality [32]. This result shows that temperature and duration combination is highly variable for different fruits, even for different varieties of the same species. In another study, Atrash et al. [28] reported that the hot water treatment significantly reduces weight loss and fruit decay of Mexican lime. Antifungal activity of hot water treatment was previously reported for different fruits, i.e., "Clementine" mandarins [33], "Satsuma" mandarins [34], banana [35], squash [36], and apples [37]. However, the optimum temperature and duration combination varied for all studies.

Besides the positive effects of HWD treatment on the prevention of weight loss and fruit decay, HWD-treated fruits of the present study were found to have higher TSS, $\mathrm{TA}$, total sugar, and VC contents as compared with untreated control fruits during cold storage. The TSS and TA are the two most important indicators of the fruits' flavour, and $\mathrm{VC}$ is an important nutritional component associated mainly with citrus fruits. VC is an important marker for the products' resistance to oxidative stress. Biosynthesis of $\mathrm{VC}$ is also reported to enhance scavenging of reactive oxygen species (ROS) [38]. VC concentration of the present study was found to be higher at the HWD-treated fruits. It was also reported to increase at some other hot water-treated fruits, i.e., orange, tomato, and banana [39, 40]. Massot et al. [41] reported that heat stress might activate genes related to VC biosynthesis. The amount of $\mathrm{VC}$ at the chill temperatures also helps to prevent chilling injury by neutralizing free radicals [42]. Previous studies with different temperature and duration combinations on different produce showed 


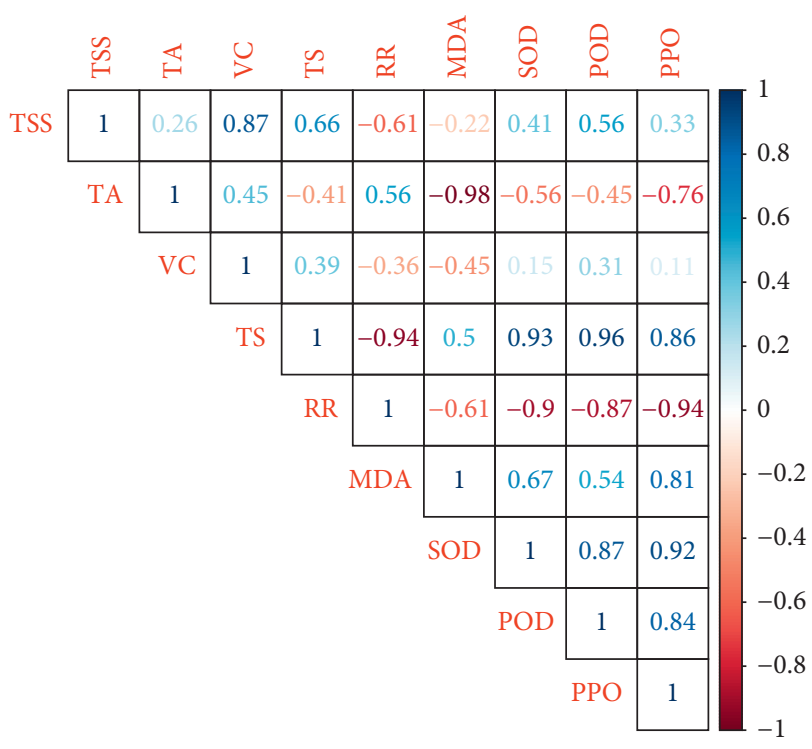

(a)

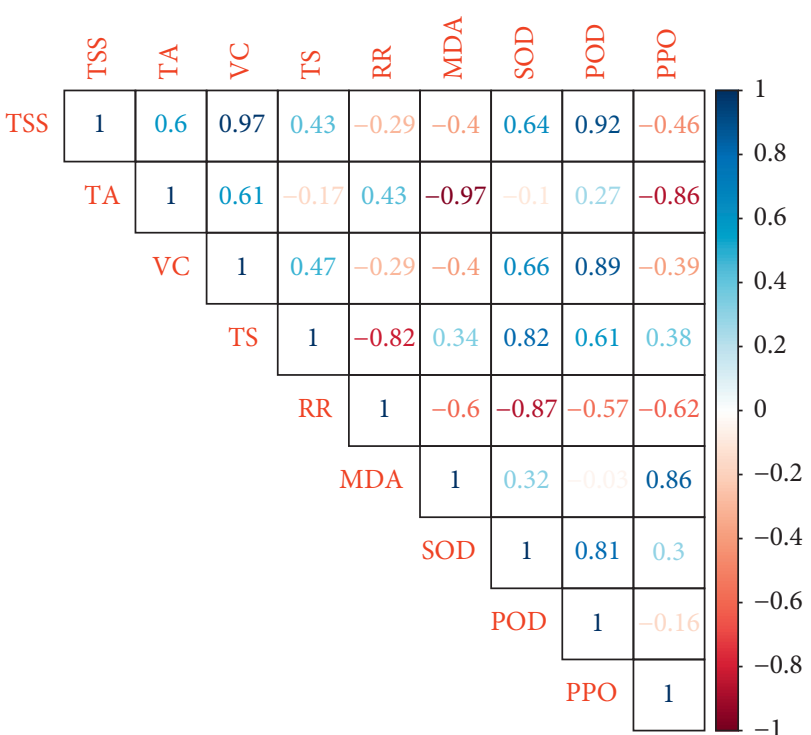

(b)

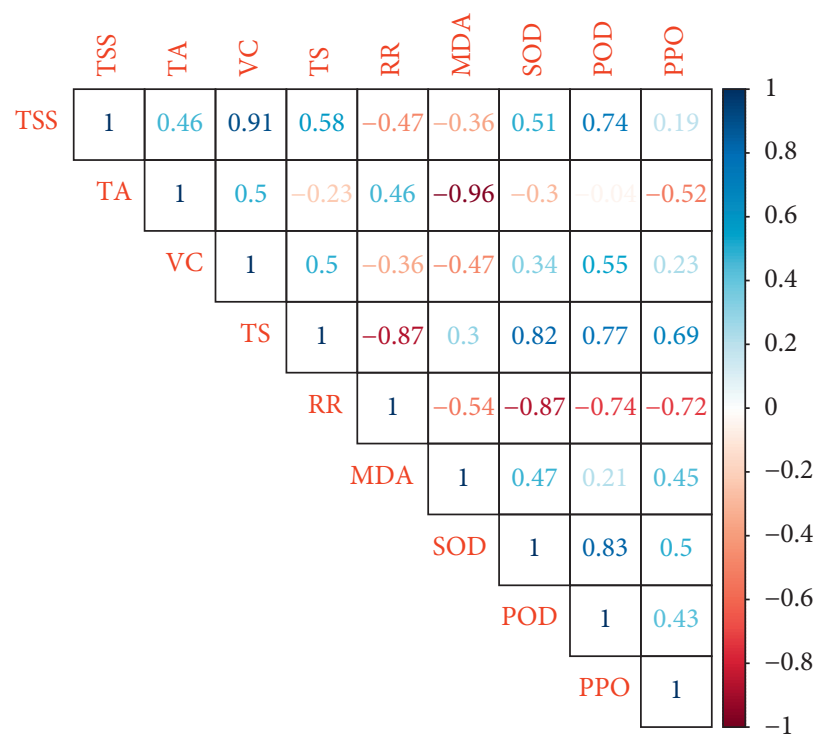

(c)

FIgURE 6: Correlation matrix based on Pearson's correlation coefficients among the biochemical quality parameters during storage. (a) The correlation matrix for HWD-treated fruits, (b)) the matrix for control group, and (c)) the overall average of all fruits (TA: titratable acidity; MDA: malondialdehyde content; VC: vitamin C; TSS: total soluble solids; PPO: polyphenoloxidase; POD: peroxidase; SOD: superoxide dismutase; RR: respiration rate; TS: total sugar). Positive correlations are displayed in blue and negative correlations in red while color intensity is proportional to the correlation coefficients.

positive effects on VC biosynthesis and ROS decrement. In one of these studies, Huan et al. [40] noted that hot water treatment (at $48^{\circ} \mathrm{C}$ for $10 \mathrm{~min}$ ) helps to maintain peach fruit quality, decrease ROS, and enhance the VC metabolism. They noted that the positive effect of hot water treatment on the prevention of ROS is a cause of enhanced VC biosynthesis which might be a cause of expressions of PpaSOD5, PpaCAT1, and PpaAPX2 in the treated fruit. In a similar study, Fatemi et al. [43] reported that the application of hot water prior to the storage of Valencia orange protects VC content as compared with untreated control fruits. In another study on "Satsuma" mandarins, Ghasemnezhad et al.
[44] observed that the higher efficacy on the prevention of chilling injury was from $50^{\circ} \mathrm{C}$ for $2 \mathrm{~min}$ application. This result supports the reasons for "carrying out present study" in which the optimum temperature and duration combination is different for different varieties of the same species. On the other hand, another study by Shen et al. [45] noted that the optimum temperature and duration combination for "Satsuma" mandarins is $50^{\circ} \mathrm{C}$ and $3 \mathrm{~min}$, and an increase in temperature was reported to decrease the efficacy of the application [45]. Similar results were reported for Mexican lime [28] and zucchini fruits [46]. In agreement with the results of the present study, Erkan et al. [31] noted that the 
heat treatments delay the reduction of VC content and TSS, but they also noted that, on the contrary to our results, it reduces the TA which causes an increase in TSS/TA ratio. Discussion of the current results with the previous studies suggests that the hot water dipping treatment is an important treatment for the protection of the postharvest storage quality of "Nanfeng" mandarins.

Respiration is among the most important factors determining the postharvest quality and storability of fresh products. It converts stored sugars into energy and increases weight loss. Respiration rate of both HWD-treated and untreated fruits of the present study was found to decrease during cold storage, but was found to be lower at the HWDtreated fruits, which explains the lesser weight loss at the HWD-treated fruits. Similarly, Opio et al. [47] noted that hot water treatment reduces the respiration rate and ethylene production of lime fruits during storage. Some other studies suggest that hot water treatment has no clear influence on the respiration rate, i.e., on citrus fruit [48] and on peach [40].

Malondialdehyde (MDA) is the end product of lipid peroxidation and its content is considered as a biomarker of oxidative damage [49]. MDA content is also known to increase while chilling injury increases [16]. Similarly, Fahmy et al. [50] suggested that the MDA equivalent is related to oxidative stress of the cucumber fruits and could be used as an indicator of damages at the cell membrane. In the present study, the MDA content of the HWD-treated fruits was found to be lower than that of the untreated control fruits during the whole storage duration. Similar results were reported by Tutan and Ekmekçi [51] for MDA content in chickpea fruits. In a previous study, hot water treatment was similarly reported to reduce the MDA concentration during the storage of peach fruits [40]. In a more comprehensive study, Lafuente et al. [52] reported that chilling favors degradation of lipids and proteins and heat conditioning at $37^{\circ} \mathrm{C}$ for 3 days enhances the repression of genes in coldstored "Fortuna" mandarins which are involved in lipid degradation and affects membrane permeability. Heat conditioning is reported to express different genes that encode late embryogenesis abundant (LEA) proteins and to reduce ROS formation which is highly associated with membrane damage.

Superoxide dismutase (SOD) and peroxidase (POD) enzymes are reported to alleviate lipid peroxidation [22, 23], while polyphenoloxidase (PPO) enzymes are known to enhance disease resistance in plant tissues [24]. The SOD and POD enzymes are also named as defense-related enzymes [24]. POD is also known to prevent cells by scavenging free radicals under stress $[23,53]$. In the present study, the SOD, POD, and PPO activities were found to be higher at the HWD-treated fruits as compared with the untreated control fruits at the end of the cold storage period. Although the SOD and POD activities were higher at the HWD-treated fruits at the end of the cold storage period, both SOD and POD activities were lower at the untreated control fruits during the initial periods of the cold storage. Similar results were previously reported by Yun et al. [48] for SOD and POD activities on citrus fruits. They noted that the
SOD and POD activities were higher at the treated fruits in the first 6 days of storage and then it decreased below to control treatments and then increased again. So, the SOD and POD activities were noted to fluctuate during the storage period. In agreement with the present study, the activities of PPO and POD were reported to decrease at the longan fruits with the hot water treatment at $50^{\circ} \mathrm{C}$ for $10 \mathrm{~min}$ [54]. Higher activity of SOD and reduced decay was then noted for sweet cherry fruit [55]. PPO and POD were previously reported to be responsible for the oxidation of phenolics in plant cells into antimicrobial quinones and protect plants from pathogens [56]. Similar to present results, HWD was previously noted to enhance the activities of PPO and POD in muskmelon fruits [30]. In line with the previous literature studies, it might be suggested that the increase in the duration exposed to low temperatures increases the SOD and POD activities of the HWD-treated fruits. This suggests that the fruits' SOD and POD activities are activated by both the preconditioning with heat treatment and the duration of exposure to the low temperatures. Present results suggest that the activation of the SOD and POD enzymes is highly related to the respiratory activities of the fresh products. It was found that the SOD and POD activities of the HWD-treated fruits are lower than those of the untreated control fruits until the fruits reach the lowest respiration peak, and then SOD and POD enzymes are activated with the increasing trend of respiration of the fruits. This shows that the activities of SOD and POD enzymes are highly influenced by heat treatment, but also interrelated with the respiration rate. Moreover, the PPO activity was found to be highly activated with the application of hot water dipping treatment.

Since Pearson correlation studies resulted with a moderate positive correlation between the MDA and the enzymatic activities, results of the present study suggested that the activities of antioxidants (VC and phenolics) and defense-related enzymes (SOD, POD, and PPO) are activated by hot water dipping and effectively reduced the MDA content and accumulation of ROS. The MDA was previously reported to have a moderate correlation with the PPO and POD but to have a negligible correlation with SOD [57]. The weak negative correlation between the VC and MDA contents showed that the increase in the MDA content negatively affects the vitamin $\mathrm{C}$ content. The high correlation among the enzymatic activities at the HWD-treated fruits suggested that the HWD treatment is highly advantageous to improve the storability of "Nanfeng" mandarins by preventing fruit senescence.

\section{Conclusions}

Results of the present study showed that, among the tested hot water temperatures and dipping durations, the most powerful treatment for an effective decay and weight loss prevention at the "Nanfeng" mandarins is the HWD at $50^{\circ} \mathrm{C}$ for $3 \mathrm{~min}$. This treatment was found to reduce the decay rate to only about $4.00 \%$ in 90 days of storage. Results also showed that the HWD treatment is effective in preventing the loss of TSS, TS, TA, and VC contents of the fruits. It was 
also noted from the further studies that the respiration rate and MDA content are significantly reduced with the HWD treatment. Results also showed that the HWD treatment is effective in increasing the activities of defense-related enzymes (SOD, POD, and PPO) at mandarins which reduces the fruit senescence and improves the storability of the fresh produce. Results also suggested that the activities of SOD and POD enzymes can be enhanced with the hot water treatment but highly dependent on the respiration rate of the fruits.

\section{Data Availability}

The statistical data used to support the findings of this study are available from the corresponding author upon request.

\section{Disclosure}

İbrahim Kahramanoğlu and Chuying Chen should be considered co-first authors.

\section{Conflicts of Interest}

The authors declare no conflicts of interest.

\section{Authors' Contributions}

I.K. and C.C. contributed equally to this work and prepared the original draft. J.C. and C.W. conceptualized the study; C.C. and Y.C. performed formal analysis and investigated the data and were responsible for methodology; C.C., C.W., Y.C., and Z.G. validated the data; C.C. and C.W. were involved in data curation; I.K. and C.W. reviewed and edited the manuscript; J.C. supervised the study and was responsible for resources and involved in project administration and funding acquisition. İbrahim Kahramanoğlu and Chuying Chen contributed equally to this work.

\section{References}

[1] A. M. Connor, J. J. Luby, J. F. Hancock, S. Berkheimer, and E. J. Hanson, "Changes in fruit antioxidant activity among blueberry cultivars during cold-temperature storage," Journal of Agricultural and Food Chemistry, vol. 50, no. 4, pp. 893898, 2002.

[2] J. W. Herbert, W. Reuther, and H. W. Lawton, History and Development of the Citrus Industry, University of California Press, Berkeley, 1943.

[3] FAO, FAO Statistics Division, FAO, Rome, Italy, 2019, http:// www.fao.org/faostat/en/\#data/QC.

[4] C. Turra, C. E. d. F. Vian, F. A. G. Nielsen, P. S. Santos, and L. F. d. F. Penteado, "Overview of the Brazilian citriculture certification," Journal of Agricultural and Environmental Ethics, vol. 27, no. 4, pp. 663-679, 2014.

[5] R. E. Henriod, "Postharvest characteristics of navel oranges following high humidity and low temperature storage and transport," Postharvest Biology and Technology, vol. 42, no. 1, pp. 57-64, 2006.

[6] R. Porat, B. Weiss, L. Cohen, A. Daus, and N. Aharoni, "Reduction of postharvest rind disorders in citrus fruit by modified atmosphere packaging," Postharvest Biology and Technology, vol. 33, no. 1, pp. 35-43, 2004.
[7] S. Sdiri, A. Salvador, I. Farhat, P. Navarro, and C. Besada, "Influence of postharvest handling on antioxidant compounds of Citrus fruits," in Citrus: Molecular Phylogeny, Antioxidant Properties and Medicinal Uses, K. Hayat, Ed., pp. 73-94, Nova Science Publishers., New York, NY, USA, 2014.

[8] E. Feliziani and G. Romanazzi, "Pre-harvest application of synthetic fungicides and alternative treatments to control postharvest decay of fruit," Steward Postharvest Reviws, vol. 3, pp. 1-6, 2013.

[9] P. Kinay, M. F. Mansour, F. Mlikota Gabler, D. A. Margosan, and J. L. Smilanick, "Characterization of fungicide-resistant isolates of Penicillium digitatum collected in California," Crop Protection, vol. 26, no. 4, pp. 647-656, 2007.

[10] H. A. R. Suleria, M. S. Butt, F. M. Anjum, F. Saeed, and N. Khalid, "Onion: nature protection against physiological threats," Critical Reviews in Food Science and Nutrition, vol. 55, no. 1, pp. 50-66, 2015.

[11] Z. Tietel, E. Lewinsohn, E. Fallik, and R. Porat, "Importance of storage temperatures in maintaining flavor and quality of mandarins," Postharvest Biology and Technology, vol. 64, no. 1, pp. 175-182, 2012.

[12] A. A. Kader and M. L. Arpaia, "Postharvest handling systems: subtropical fruits," in Postharvest Technology of Horticultural Crops, A. A. Kader, Ed., pp. 375-384, Regents of the University of California, Division of Agricultural and Natural Resources, Oakland, CA, USA, Third edition, 2002.

[13] C. Chen, Z. Nie, C. Wan, and J. Chen, "Preservation of Xinyu Tangerines with an edible coating using Ficus hirta vahl. Fruits extract-incorporated chitosan," Biomolecules, vol. 9, no. 2, p. 46, 2019.

[14] C. Chen, N. Cai, J. Chen, X. Peng, and C. Wan, "Chitosanbased coating enriched with hairy fig (Ficus hirta vahl.) fruit extract for "Newhall" navel orange preservation," Coatings, vol. 8, no. 12, p. 445, 2018.

[15] C. Singh, H. K. Sharma, and B. C. Sarkar, "Influence of process conditions on the mass transfer during osmotic dehydration of coated pineapple samples," Journal of Food Processing and Preservation, vol. 34, pp. 700-714, 2010.

[16] A. A. Lo'ay and H. D. Dawood, "Tolerance of "Baladi" Mandarin fruits to cold storage by postharvest pectin/PVA blend with ascorbic acid treatment," Scientia Horticulturae, vol. 256, Article ID 108637, , 2019.

[17] S.-A. Haider, S. Ahmad, A. Sattar Khan, M. A. Anjum, M. Nasir, and S. Naz, "Effects of salicylic acid on postharvest fruit quality of "Kinnow" Mandarin under cold storage," Scientia Horticulturae, vol. 259, p. 108843, 2020.

[18] J. Chen, Y. Shen, C. Chen, and C. Wan, "Inhibition of key citrus postharvest fungal strains by plant extracts in vitro and in vivo: a review," Plants, vol. 8, no. 2, p. 26, 2019.

[19] Z. Xin, Q. OuYang, C. Wan et al., "Isolation of antofine from Cynanchum atratum BUNGE (Asclepiadaceae) and its antifungal activity against Penicillium digitatum," Postharvest Biology and Technology, vol. 157, p. 110961, 2019.

[20] E. Bal, "Effects of essential oil treatments combined with hot water treatment on improving postharvest life of sweet cherry," Fruits, vol. 67, no. 4, pp. 285-291, 2012.

[21] D. G. Alvindia and M. A. Acda, "Revisiting the efficacy of hot water treatment in managing anthracnose and stem-end rot diseases of mango cv. "Carabao"," Crop Protection, vol. 67, pp. 96-101, 2015.

[22] A. R. Ballester, M. T. Lafuente, and L. González-Candelas, "Spatial study of antioxidant enzymes, peroxidase and phenylalanine ammonia-lyase in the citrus fruit-Penicillium 
digitatum interaction," Postharvest Biology and Technology, vol. 39, no. 2, pp. 115-124, 2006.

[23] J. Sels, J. Mathys, B. M. A. De Coninck, B. P. A. Cammue, and M. F. C. De Bolle, "Plant pathogenesis-related (PR) proteins: a focus on PR peptides," Plant Physiology and Biochemistry, vol. 46, no. 11, pp. 941-950, 2008.

[24] Y. Gao, C. Kan, C. Wan, C. Chen, M. Chen, and J. Chen, "Quality and biochemical changes of navel orange fruits during storage as affected by cinnamaldehyde-chitosan coating," Scientia Horticulturae, vol. 239, pp. 80-86, 2018.

[25] AOAC, Official Method of Analysis of the Association of Official Analytical Chemistry, AOAC, Arlington, VA, USA, 15th edition, 1990.

[26] D. M. Hodges, J. M. DeLong, C. F. Forney, and R. K. Prange, "Improving the thiobarbituric acid-reactive-substances assay for estimating lipid peroxidation in plant tissues containing anthocyanin and other interfering compounds," Planta, vol. 207, no. 4, pp. 604-611, 1999.

[27] İ. Kahramanoğlu, "Introductory chapter: postharvest physiology and technology of horticultural crops," in Postharvest Handling, pp. 1-5, InTech Open, London, UK, 2017.

[28] S. Atrash, A. Ramezanian, M. Rahemi, R. M. Ghalamfarsa, and E. Yahia, "Antifungal effects of savory essential oil, gum Arabic, and hot water in Mexican lime fruits," HortScience, vol. 53, no. 4, pp. 524-530, 2018.

[29] X. Wang, F. Xu, J. Wang, P. Jin, and Y. Zheng, "Bacillus cereus AR156 induces resistance against Rhizopus rot through priming of defense responses in peach fruit," Food Chemistry, vol. 136, no. 2, pp. 400-406, 2013.

[30] L. Yuan, Y. Bi, Y. Ge, Y. Wang, Y. Liu, and G. Li, "Postharvest hot water dipping reduces decay by inducing disease resistance and maintaining firmness in muskmelon (Cucumis melo L.) fruit," Scientia Horticulturae, vol. 161, pp. 101-110, 2013.

[31] M. Erkan, M. Pekmezci, İ. Karaşahin, and H. Uslu, "Reducing chilling injury and decay in stored "Clementine" mandarins with hot water and curing treatments," European Journal of Horticultural Science, vol. 70, pp. 183-188, 2005.

[32] P. Hong, W. Hao, J. Luo, S. Chen, M. Hu, and G. Zhong, "Combination of hot water, Bacillus amyloliquefaciens HF-01 and sodium bicarbonate treatments to control postharvest decay of Mandarin fruit," Postharvest Biology and Technology, vol. 88, pp. 96-102, 2014.

[33] L. Palou, J. Usall, J. A. Muñoz, J. L. Smilanick, and I. Viñas, "Hot water, sodium carbonate, and sodium bicarbonate for the control of postharvest green and blue molds of clementine mandarins," Postharvest Biology and Technology, vol. 24, no. 1, pp. 93-96, 2002.

[34] S.-I. Hong, H.-H. Lee, and D. Kim, "Effects of hot water treatment on the storage stability of satsuma Mandarin as a postharvest decay control," Postharvest Biology and Technology, vol. 43, no. 2, pp. 271-279, 2007.

[35] S. Bazie, A. Ayalew, and K. Woldetsadik, "Integrated management of postharvest banana anthracnose (Colletotrichum musae) through plant extracts and hot water treatment," Crop Protection, vol. 66, pp. 14-18, 2014.

[36] D. Chalupowicz, S. Alkalai-Tuvia, M. Zaaroor-Presman, and E. Fallik, "The potential use of hot water rinsing and brushing technology to extend storability and shelf life of sweet acorn squash (Cucurbita pepo L.)," Horticulturae, vol. 4, no. 3, p. 19, 2018.

[37] A. D. Francesco, M. Mari, and R. Roberti, "Defense response against postharvest pathogens in hot water treated apples," Scientia Horticulturae, vol. 227, pp. 181-186, 2018.
[38] S. P. Singh and Z. Singh, "Dynamics of enzymatic and nonenzymatic antioxidants in Japanese plums during storage at safe and lethal temperatures," LWT-Food Science and Technology, vol. 50, no. 2, pp. 562-568, 2013.

[39] Y. Imahori, J. Bai, and E. Baldwin, "Antioxidative responses of ripe tomato fruit to postharvest chilling and heating treatments," Scientia Horticulturae, vol. 198, pp. 398-406, 2016.

[40] C. Huan, S. Han, L. Jiang et al., "Postharvest hot air and hot water treatments affect the antioxidant system in peach fruit during refrigerated storage," Postharvest Biology and Technology, vol. 126, pp. 1-14, 2017.

[41] C. Massot, D. Bancel, F. L. Lauri et al., "High temperature inhibits ascorbate recycling and light stimulation of the ascorbate pool in tomato despite increased expression of biosynthesis genes," PLoS One, vol. 8, no. 12, Article ID e84474, 2013.

[42] F. Naser, V. Rabiei, F. Razavi, and O. Khademi, "Effect of calcium lactate in combination with hot water treatment on the nutritional quality of persimmon fruit during cold storage," Scientia Horticulturae, vol. 233, pp. 114-123, 2018.

[43] S. Fatemi, M. Jafarpour, and S. Eghbalsaied, "Study of the effect of Thymus vulgaris and hot water treatment on storage life of orange (Citrus sinensis CV. Valencia)," Journal of Medicinal Plants Research, vol. 6, no. 6, pp. 968-971, 2012.

[44] M. Ghasemnezhad, K. Marsh, R. Shilton, M. Babalar, and A. Woolf, "Effect of hot water treatments on chilling injury and heat damage in "Satsuma" mandarins: antioxidant enzymes and vacuolar ATPase, and pyrophosphatase," Postharvest Biology and Technology, vol. 48, no. 3, pp. 364-371, 2008.

[45] Y. Shen, L. Zhong, Y. Sun, J. Chen, D. Liu, and X. Ye, "Influence of hot water dip on fruit quality, phenolic compounds and antioxidant capacity of Satsuma Mandarin during storage," Food Science and Technology International, vol. 19, no. 6, pp. 511-521, 2012.

[46] M. Zhang, W. Liu, C. Li et al., "Postharvest hot water dipping and hot water forced convection treatments alleviate chilling injury for zucchini fruit during cold storage," Scientia Horticulturae, vol. 249, pp. 219-227, 2019.

[47] P. Opio, P. Jitareerat, N. Pongprasert, C. Wongs-Aree, Y. Suzuki, and V. Srilaong, "Efficacy of hot water immersion on lime (Citrus auranifolia, Swingle cv. Paan) fruit packed with ethanol vapor in delaying chlorophyll catabolism," Scientia Horticulturae, vol. 224, pp. 258-264, 2017.

[48] Z. Yun, H. Gao, P. Liu et al., "Comparative proteomic and metabolomic profiling of citrus fruit with enhancement of disease resistance by postharvest heat treatment," BMC Plant Biology, vol. 13, pp. 1-16, 2013.

[49] F. Cai, L. J. Mei, X. L. An, S. Gao, L. Tang, and F. Chen, "Lipid peroxidation and antioxidant responses during seed germination of Jatropha curcas," International Journal of Agriculture and Biology, vol. 13, pp. 25-30, 2011.

[50] K. Fahmy, K. Nakano, and F. Violalita, "Investigation on quantitative index of chilling injury in cucumber fruit based on the electrolyte leakage and malondialdehyde content," International Journal on Advanced Science, Engineering and Information Technology, vol. 5, no. 3, pp. 222-225, 2015.

[51] Öu Turan and Y. Ekmekçi, "Activities of photosystem II and antioxidant enzymes in chickpea (Cicer arietinum L.) cultivars exposed to chilling temperatures," Acta Physiologiae Plantarum, vol. 33, no. 1, pp. 67-78, 2011.

[52] M. T. Lafuente, B. Establés-Ortíz, and L. González-Candelas, "Insights into the molecular events that regulate heat-induced 
chilling tolerance in citrus fruits," Frontiers in Plant Science, vol. 8, p. 1113, 2017.

[53] D. F. Klessig and J. Malamy, "The salicylic acid signal in plants," Plant Molecular Biology, vol. 26, no. 5, pp. 1439-1458, 1994.

[54] Y.-F. Zhao, H.-T. Lin, Y.-F. Lin, Y.-H. Chen, and Y.-L. Ming, "Effect of heat treatment on browning delaying and phenolics metabolism in pericarp of harvested longan fruit," Modern Food Science and Technology, vol. 30, pp. 218-224, 2014.

[55] L. Wang, P. Jin, J. Wang, H. Gong, S. Zhang, and Y. Zheng, "Hot air treatment induces resistance against blue mold decay caused by Penicillium expansum in sweet cherry (Prunus cerasus L.) fruit," Scientia Horticulturae, vol. 189, pp. 74-80, 2015.

[56] M. Mohammadi and H. Kazemi, "Changes in peroxidase and polyphenol oxidase activities in susceptible and resistant wheat heads inoculated with Fusarium graminearum and induced resistance," Plant Science, vol. 162, no. 4, pp. 491-498, 2002.

[57] G. Adiletta, M. Pasquariello, L. Zampella, F. Mastrobuoni, M. Scortichini, and M. Petriccione, "Chitosan coating: a postharvest treatment to delay oxidative stress in loquat fruits during cold storage," Agronomy, vol. 8, no. 4, p. 54, 2018. 